\title{
¿Quién puede ejercer la docencia en nuestras facultades de medicina?
}

\section{Who is able to teach in our medical schools?}

Correspondencia Percy Herrera-Añazco silamud@gmail.com

Recibido: 23/02/2017 Aprobado: 01/03/2017

Citar como: Herrera-Añazco $P$, Valenzuela-Rodriguez G. ¿Quién puede ejercer la docencia en nuestras facultades de medicina? Acta Med Peru. 2017;34(1):68-9

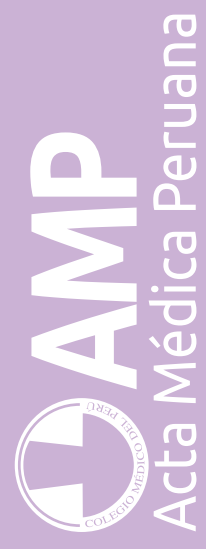

\author{
Percy Herrera-Añazco ${ }^{1,2}$, Germán Valenzuela-Rodriguez ${ }^{3}$ \\ 1 Hospital Nacional Dos de Mayo. Lima, Perú. \\ 2 Universidad Peruana de Ciencias Aplicadas. Lima, Perú. \\ 3 Centro de Investigación, Clínica Delgado, AUNA. Lima, Perú.
}

\section{Sr. Editor:}

El número de médicos en el Perú no garantiza una cobertura adecuada a toda la población ${ }^{[1]}$. La posibilidad de cubrir ésta demanda con la formación de más médicos es bienvenida; sin embargo, se ha cuestionado si este aumento va de la mano con una supervisión de la calidad de su enseñanza ${ }^{[2]}$.

En el Perú, existen 52 facultades de medicina, 16 de las cuales se encuentran en Lima. El Colegio Médico del Perú, consciente de que una proliferación no controlada de facultades de medicina sin supervisión de la calidad de sus egresados puede poner en riesgo la salud de los peruanos, ha planteado una serie de medidas entre las que se encuentra la regulación de los campos clínicos ${ }^{[2]}$.

Una preocupación no contemplada es que no se sabe quiénes serán los encargados de la enseñanza del cada vez mayor número de estudiantes de medicina, pues en nuestro país, algunos profesores de las facultades de medicina no están capacitados para dictar los cursos a su cargo [3]. La noticia de que la Superintendencia Nacional de Educación Superior (SUNEDU) exigía que para ser profesor universitario se cuente con el grado académico de maestro ${ }^{[4]}$ fue celebrada. Esta medida, aunque imperfecta por la heterogeneidad de la calidad de las maestrías ofrecidas en el país, representaba una forma de asegurarnos de que los implicados cuenten con la capacitación suficiente para ejercer el rol de educadores de un nivel superior, en una realidad universitaria peruana que algunos calificarían en el mejor de los casos de mediocre.

El oficio N 915-2016/SUNEDU 02 de la SUNEDU que da respuesta a los oficios enviados por la Universidad Peruana Cayetano Heredia sobre los artículos 75 y 82 del estatuto de la Ley Universitaria $N^{\circ} 30220$ que regulan el ejercicio de la docencia, flexibiliza este requisito. Según este oficio, para ser profesor universitario en la carrera de medicina no se necesitaría tener el grado de maestro dado que el título de especialista sería equivalente a una maestría.

Ambas formaciones tienen objetivos diferentes. Mientras la primera prepara para ser maestro en un área, en la segunda, el médico se vuelve experto en un área asistencial de la medicina, como lo señala el artículo 3 de la Ley 30453 que dice textualmente: "la residencia médica es una modalidad académica de capacitación y entrenamiento presencial e intensivo con el objetivo de lograr la más alta capacitación cognoscitiva y de competencias en las diferentes ramas de la profesión" [5], pero no la docencia. Si bien es cierto que algunos de nuestros profesores no contaron con éste grado académico y destacaron en la docencia, no todos nacen con ese don y probablemente los que lo tengan no serán suficientes para enseñar en las 52 facultades a nivel nacional. Ello empeora, considerando que algunos han cuestionado la calidad del residentado médico en nuestro país ${ }^{[6]}$.

La necesidad de profesores es apremiante, pero más la de profesores adecuadamente capacitados. Por tal motivo, esta flexibilización posiblemente esté creando un problema con potenciales implicancias para la salud pública del país que nuestras autoridades deberían replantear. 


\section{REFERENCIAS BIBLIOGRÁFICAS}

1. Carrasco-Cortez V, Lozano-SalazarE, Velásquez-Pancca E. Análisis actual y prospectivo de la oferta y la demanda de médicos en el Perú 2005-2011. Acta Med Peru. 2008;25(1):22-9.

2. Mayta-Tristán $P$, Cuentas $M$, Núñez-Vergara $M$. Responsabilidad de las instituciones ante la proliferación de escuelas de medicina en el Perú. Acta Med Peru. 2016;33(3):178-82.

3. Pereyra-Elías R, Huaccho-Rojas J, Taype-Rondán A, Mejía CR, Mayta-Tristan P. Publicación y factores asociados en docentes universitarios de investigación científica en escuelas de medicina del Perú. Rev Peru Med Exp Salud Publica. 2014;31(3):424-30.

4. Ley Universitaria $N^{\circ} 30220$ (8 de julio de 2014).

5. Ley del Sistema Nacional de Residentado Médico (SINAREME) Nº 30453 (20 de mayo de 2016).

6. Miní E, Medina J, Peralta V, Rojas L, Butron J, Gutiérrez EL. Programa de residentado médico: percepciones de los médicos residentes en hospitales de Lima y Callao. Rev Peru Med Exp Salud Publica. 2015;32(2):303-10.

\section{Las ediciones anteriores de Acta Médica Peruana están disponibles en:}

\section{www.redalyc.org}

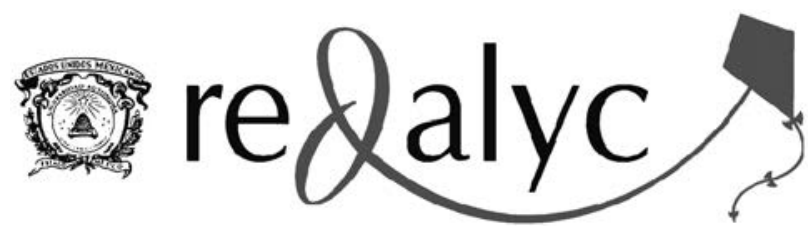

